\title{
Prognostic and predictive value of VEGF, sVEGFR-2 and CEA in mCRC studies comparing cediranib, bevacizumab and chemotherapy
}

\author{
J M Jürgensmeier ${ }^{\star}{ }^{1}$, H-J Schmoll ${ }^{2}$, J D Robertson ${ }^{1}$, L Brooks ${ }^{1}$, M Taboada ${ }^{1}$, S R Morgan ${ }^{1}$, \\ D Wilson ${ }^{1}$ and $\mathrm{P}$ M Hoff $\mathrm{H}^{3,4}$ \\ ${ }^{1}$ Translational Sciences, Oncology, AstraZeneca, Alderley Park, Macclesfield SK10 4TG, UK; ${ }^{2}$ Martin Luther University, Halle-Saale, \\ Halle 06120, Germany; ${ }^{3}$ Instituto do Cancer do Estado de São Paulo, Universidade de São Paulo, Av. Dr Arnaldo 251, São Paulo, \\ Brazil and ${ }^{4}$ Centro de Oncologia, Hospital Sírio Libanês, São Paulo 01308-050, Brazil
}

Background: The prognostic/predictive value of potential vascular endothelial growth factor (VEGF) signalling biomarkers was evaluated retrospectively using samples from two randomized Phase III studies (HORIZON II and III) investigating cediranib in metastatic colorectal cancer (mCRC).

Methods: Baseline levels of VEGF, soluble VEGF receptor-2 (sVEGFR-2) and carcinoembryonic antigen (CEA) were measured in plasma/serum samples collected from patients participating in HORIZON II ( $n=860$; FOLFOX/XELOX plus cediranib $20 \mathrm{mg}$ $(n=502)$ or placebo $(n=358))$ and HORIZON III $(n=1422$; mFOLFOX6 plus cediranib $20 \mathrm{mg}(n=709)$ or bevacizumab $(n=713))$. Median biomarker baseline levels determined cutoff values for the patient subgroups.

Results: Baseline data were available for 88-97\% of patients/study (> 2000 patients). In both the studies, high baseline VEGF and CEA were associated with worse outcomes for progression-free survival (PFS) and overall survival (OS) independent of treatment (HORIZON II OS: VEGF, hazard ratio (HR) =1.35 (95\% confidence interval (CI): 1.12-1.63); CEA, HR=1.63 (1.36-1.96); HORIZON III OS: VEGF, HR=1.32 (1.12-1.54); CEA, HR=1.50 (1.29-1.76)). sVEGFR-2 was not prognostic for PFS/OS. Baseline VEGF and CEA were not predictive for PFS/OS outcome to cediranib treatment; low sVEGFR-2 was associated with a trend towards improved cediranib effect in HORIZON II.

Conclusion: Baseline VEGF and CEA levels were treatment-independent prognostic biomarkers for PFS and OS in both the studies.

Anticancer drugs that target vascular endothelial growth factor (VEGF) signalling have increasingly become integrated into cancer therapy for a range of tumour types; however, a patient selection strategy to identify those patients who benefit most from these treatments has yet to be developed. Although multiple hypotheses have been explored, most often in small and single-arm studies, biomarkers that could facilitate appropriate patient selection have not been established. There remains a need to identify both prognostic biomarkers, which provide information about cancer progression irrespective of treatment, and predictive biomarkers, which provide information about the effectiveness of a particular therapy in subsets of patients.

*Correspondence: Dr JM Jürgensmeier; E-mail: juliane.jurgensmeier@astrazeneca.com

Previous presentation: ASCO Congress, Chicago, IL, 3-7 June 2011 (poster presentation).

Received 14 December 2012; revised 23 January 2013; accepted 29 January 2013; published online 28 February 2013

(c) 2013 Cancer Research UK. All rights reserved 0007-0920/13 
VEGF is the most widely studied angiogenic factor and is considered critically important for tumour angiogenesis; overexpression of VEGF is known to promote tumour progression and metastatic spread. VEGF is generally recognised as a negative prognostic factor for patient outcome in many tumour types (Amaya et al, 1997; Jacobsen et al, 2000; des Guetz et al, 2006; Longo and Gasparini, 2007; Jantus-Lewintre et al, 2011) and a potential predictive factor for treatment with VEGF signalling inhibitors, including VEGF receptor (VEGFR) tyrosine kinase inhibitors (TKIs) (Miles et al, 2010). The soluble form of VEGFR-2 (sVEGFR-2) contains the extracellular domains of the receptor but lacks the tyrosine kinase domain. VEGF and VEGFRs are expressed highly in metastatic colon carcinomas and tumourassociated endothelial cells (De Vita et al, 2004). As with VEGF, high levels of VEGFR-2 expression have previously been associated with worse prognoses in patients with various tumour types; however, most studies included small patient numbers (Seto et al, 2006; Xia et al, 2006; Rydén et al, 2010).

For patients with colorectal cancer (CRC), the glycoprotein carcinoembryonic antigen (CEA) has been identified as a validated marker for monitoring responses to chemotherapy (Locker et al, 2006). CEA is involved in cell adhesion and is considered a general prognostic factor in CRC patients (Andicoechea et al, 1998).

Cediranib is an oral VEGFR TKI with activity against all three VEGFRs (Wedge et al, 2005; Heckman et al, 2008). The HORIZON II and HORIZON III trials were large, randomized, double-blind Phase III studies of cediranib in patients with previously untreated metastatic CRC (mCRC). HORIZON II (ClinicalTrials.gov identifier NCT00399035) compared cediranib plus FOLFOX/XELOX with placebo plus FOLFOX/XELOX. In this trial, cediranib plus FOLFOX/XELOX showed a significant improvement in the co-primary endpoint of progression-free survival (PFS) compared with chemotherapy alone (hazard ratio (HR) $0.84, P=0.012$ ), but there was no improvement in the other co-primary endpoint of overall survival (OS) vs chemotherapy alone (HR 0.94, $P=0.571$ ) (Hoff et al, 2012). HORIZON III (ClinicalTrials.gov identifier NCT00384176) compared cediranib plus mFOLFOX6 with bevacizumab plus mFOLFOX6. There was no significant difference between the two treatment groups in the primary endpoint of PFS; however, cediranib plus mFOLFOX6 did not meet the pre-defined criteria for non-inferiority $v s$ bevacizumab plus mFOLFOX6 (HR 1.1 (95\% confidence interval (CI) $0.97-1.25) ; P=0.119)$ (Schmoll et al, 2012). Pre-specified subgroup analyses from both the studies did not reveal any subgroups of patients with clear evidence of a better or worse outcome following cediranib treatment compared with the overall patient population (Hoff et al, 2012; Schmoll et al, 2012).

In order to explore the prognostic and predictive value of potential biomarkers for VEGF signalling inhibitors in $\mathrm{mCRC}$, a retrospective analysis of baseline levels of VEGF, sVEGFR-2 and CEA was performed using blood samples obtained from patients recruited to HORIZON II and HORIZON III.

\section{PATIENTS AND METHODS}

Venous blood samples were obtained from patients participating in the HORIZON II and HORIZON III trials. This analysis included samples from all the 1422 patients randomized to mFOLFOX6 with cediranib $20 \mathrm{mg}(n=709)$ or bevacizumab $(n=713)$ in HORIZON III, as well as samples from all the 860 patients who received FOLFOX or XELOX with cediranib $20 \mathrm{mg}(n=502)$ or placebo $(n=358)$ in HORIZON II. Blood samples from those patients randomized to the cediranib $30 \mathrm{mg}$ arms in HORIZON II and HORIZON III were not included, because these treatment arms were unblinded following an end-of-Phase II analysis.
Biomarker samples were available for the analysis of VEGF and sVEGFR-2 for 808 out of 860 (94\%) and 809 out of 860 (94\%) patients, respectively, in HORIZON II and for 1254 out of 1422 $(88 \%)$ and 1258 out of $1422(88 \%)$ patients in HORIZON III, respectively. CEA data were available for 837 out of 860 (97\%) patients in HORIZON II and for 1359 out of 1422 (96\%) patients in HORIZON III.

As biomarker data were available for $88-97 \%$ of patients across both trials, it was assumed that the baseline characteristics were representative of the overall population. Additionally, patients missing the biomarker analysis had similar PFS and OS outcomes as that of the overall population. Therefore, the results observed in the group of patients with biomarker data are considered representative of the whole population in each of the trials.

Plasma samples were collected using EDTA-coated anticoagulant tubes at each study site and stored at $-70{ }^{\circ} \mathrm{C}$ at a central storage facility. Serum CEA was measured at each study site according to the local protocol as part of the HORIZON II and III clinical trials. Plasma levels of VEGF and sVEGFR-2 were measured centrally at LabCorp (Research Triangle Park, NC, USA) using commercially available solid phase ELISA kits (R\&D Systems Inc, MN, USA).

The Quantikine VEGF Immunoassay is an ELISA designed to measure VEGF165 levels in cell culture supernates, serum and plasma. It contains Sf 21-expressed, recombinant human VEGF165 and antibodies raised against the recombinant protein. Results obtained for naturally occurring human VEGF and recombinant human VEGF121 showed linear curves that were parallel to the standard curves. The range of detection for validation samples was ND to $115 \mathrm{pg} \mathrm{ml}^{-1} ; 24 \%$ were detected with a mean result of $61 \mathrm{pg} \mathrm{ml}^{-1}$. In this study, results below the lowest standard were reported as $<31.2 \mathrm{pg} \mathrm{ml}^{-1}$. Specimens giving results $>2000 \mathrm{pg} \mathrm{ml}^{-1}$ were diluted with calibrator diluent and repeated.

The Quantikine VEGF R2 Immunoassay is an immunoassay designed to measure human sVEGFR-2 in cell culture supernates, cell lysates, serum and plasma; it contains NS0-expressed recombinant human VEGFR-2/Fc chimera to quantitate the recombinant factor. Results obtained using natural human VEGFR-2 showed linear curves that were parallel to the standard curves. The range of detection for validation samples was $6635-13553 \mathrm{pg} \mathrm{ml}^{-1}$ with a mean result of $9577 \mathrm{pg} \mathrm{ml}^{-1}$. The working range for human sVEGFR-2 is $78.1-5000 \mathrm{pg} \mathrm{ml}^{-1}$. In the study, sVEGFR-2 results below the lowest standard were reported as $<78.1 \mathrm{pg} \mathrm{ml}^{-1}$ and specimens giving results $>5000 \mathrm{pg} \mathrm{ml}^{-1}$ were diluted with calibrator diluent and repeated.

Details relating to patient characteristics, including both inclusion and exclusion criteria, and treatments received for the patient populations from HORIZON II and III, are reported by Hoff et al (2012) and Schmoll et al (2012), respectively. The assay methods are described by Drevs et al (2007). Analyses were conducted by a contract research organisation, which was blinded to the treatment of patients, and results were unblinded after completion of analyses.

Statistical methods. Details relating to sample size requirements for the HORIZON II and III studies are reported by Hoff et al (2012) and Schmoll et al (2012), respectively.

The median baseline plasma/serum levels of VEGF, sVEGFR-2 and CEA across all patients in HORIZON II and HORIZON III were used to define the low and high patient subgroups for each biomarker. For those biomarkers showing strong prognostic trends on OS based on median cutoff values, additional analyses were conducted by dividing patients into four subgroups based on the upper and lower quartiles for baseline plasma/serum level of the biomarker. For the biomarker analysis, HRs were derived from a Cox proportional hazards model with covariates for World Health Organisation (WHO) performance status, chemotherapy received 
(HORIZON II only), baseline liver function and study phase (i.e., whether or not patients contributed to an end-of-Phase II analysis in the HORIZON programme; HORIZON II only). This approach, and the covariates chosen, was the same as that used in the overall analysis of the HORIZON II and III trials. The results from the biomarker analysis presented in this manuscript relate to the endpoints of PFS and OS from the Phase III HORIZON trials.

\section{RESULTS}

Details of the baseline demographics and characteristics for the patient populations from HORIZON II and III are reported by Hoff et al (2012) and Schmoll et al (2012), respectively. At data cutoff for the two Phase III studies, 720 progression events and 523 deaths had occurred in HORIZON II and 924 progression events and 730 deaths in HORIZON III.

For each factor, baseline data were available for $>85 \%$ patients in each study (Table 1). The PFS and OS results for patients with missing VEGF, sVEGFR-2 or CEA data were similar to the results observed for the relevant overall study population, indicating that there were no concerns regarding bias by excluding these patients from the prognostic and predictive biomarker analyses.

For VEGF, the median baseline plasma level of VEGF was $98 \mathrm{pg} \mathrm{ml}^{-1}$, and the lower and upper patient quartiles were 49 and $209 \mathrm{pg} \mathrm{ml}^{-1}$, respectively. The median baseline plasma level of sVEGFR-2 used to define the high and low subgroups was $11587 \mathrm{pg} \mathrm{ml}^{-1}$. For CEA, the median baseline serum level was $50 \mathrm{ng} \mathrm{ml}^{-1}$, the lower quartile was $10 \mathrm{ng} \mathrm{ml}^{-1} \mathrm{ml}^{-1}$ and the upper quartile was $225 \mathrm{ng} \mathrm{ml}^{-1}$.

Prognostic factors. High baseline VEGF values ( $>98 \mathrm{pg} \mathrm{ml}^{-1}$ ) were associated with a worse PFS outcome compared with low baseline VEGF values in both HORIZON II and III (Figures 1A and B). High baseline VEGF levels were also associated with a worse OS outcome in both the studies (Figures $1 \mathrm{C}$ and D; Table 2). This finding is supported by a further analysis of OS outcome in which the population was divided into quartiles according to baseline VEGF levels; patients in the quartile with the highest baseline VEGF values ( $>209 \mathrm{pg} \mathrm{ml}^{-1}$ ) had the worst OS outcome, whereas those in the quartile with the lowest baseline values $\left(\leqslant 49 \mathrm{pg} \mathrm{ml}^{-1}\right.$ ) had the best outcome (Table 2).

No correlations were found between baseline VEGF level and WHO performance status, sex, weight or body mass index in either HORIZON II or III. In addition, no significant correlations were observed between baseline VEGF and ethnicity in either trial, although median VEGF levels were lower in HORIZON II patients from East Asia (China, Taiwan and Korea; $73 \mathrm{pg} \mathrm{ml}^{-1}$ ), in particular China (63 $\left.\mathrm{pg} \mathrm{ml}^{-1}\right)$, compared with patients from other countries $\left(122 \mathrm{pg} \mathrm{ml}^{-1}\right)$; the observed differences were not related to weight or body mass index as no correlation was observed between these characteristics and VEGF levels.

HRs calculated for high baseline sVEGFR-2 levels compared with low levels (independent of treatment) revealed that sVEGFR-2 plasma levels were not prognostic for PFS or OS in either HORIZON II (PFS: HR 0.99 (95\% CI 0.85-1.15); OS: HR 0.92 (95\% CI 0.77-1.10)) or HORIZON III (PFS: HR 0.98 (95\% CI 0.86-1.13); OS: HR 0.98 (95\% CI 0.84-1.15)). In HORIZON II, patients in both the high and low sVEGFR-2 subgroups had a median PFS of 8.3 months, while median OS was slightly increased in the high baseline sVEGFR-2 subgroup (21.0 months vs 18.4 months in the low sVEGFR-2 subgroup). In HORIZON III, patients in the high baseline sVEGFR-2 subgroup had a slightly increased median PFS and OS compared with those in the low baseline subgroup (PFS: 10.4 months vs 9.6 months; OS: 22.6 months vs 21.4 months).

\begin{tabular}{|c|c|c|}
\hline & $\begin{array}{l}\text { HORIZON II } \\
(\boldsymbol{N}=860) \\
n(\%)\end{array}$ & $\begin{array}{l}\text { HORIZON III } \\
\left(\begin{array}{c}N=1422) \\
n(\%)\end{array}\right.\end{array}$ \\
\hline \multicolumn{3}{|l|}{ VEGF $^{a}$} \\
\hline $\begin{array}{l}\text { High } \\
\text { Low } \\
\text { Missing }\end{array}$ & $\begin{array}{c}448(52.1) \\
360(41.9) \\
52(6.0)\end{array}$ & $\begin{array}{l}573(40.3) \\
681(47.9) \\
168(11.8)\end{array}$ \\
\hline \multicolumn{3}{|c|}{ sVEGFR-2 ${ }^{a}$} \\
\hline $\begin{array}{l}\text { High } \\
\text { Low } \\
\text { Missing }\end{array}$ & $\begin{array}{c}393(45.7) \\
416(48.4) \\
51(5.9)\end{array}$ & $\begin{array}{l}644(45.3) \\
614(43.2) \\
164(11.5)\end{array}$ \\
\hline \multicolumn{3}{|l|}{ CEA $^{a}$} \\
\hline $\begin{array}{l}\text { High } \\
\text { Low } \\
\text { Missing }\end{array}$ & $\begin{array}{c}386(44.9) \\
451(52.4) \\
23(2.7)\end{array}$ & $\begin{array}{c}616(43.3) \\
743(52.3) \\
63(4.4)\end{array}$ \\
\hline \multicolumn{3}{|c|}{$\begin{array}{l}\text { Abbreviations: CEA }=\text { carcinoembryonic antigen; sVEGFR-2 = soluble vascular endothelia } \\
\text { growth factor (VEGF) receptor- } 2 \text {. } \\
{ }^{2} \text { Cutoffs used to define the high and low subgroups: VEGF, } 98 \mathrm{pg} \mathrm{ml}^{-1} \text {; } \\
\text { sVEGFR-2, } 11587 \mathrm{pg} \mathrm{ml}^{-1} \text {; and CEA, } 50 \mathrm{ng} \mathrm{ml}^{-1} \text {. }\end{array}$} \\
\hline
\end{tabular}

High baseline CEA values were associated with a worse overall outcome than low baseline CEA levels for PFS and OS in HORIZON II and III (Figure 2; Table 3). Further analysis of OS outcome according to quartile analysis by CEA levels showed that patients with the lowest baseline CEA values $\left(\leqslant 10 \mathrm{pg} \mathrm{ml}^{-1}\right)$ had the best OS outcome in both the studies.

Predictive factors. There was no evidence to suggest that baseline plasma/serum levels of either VEGF or CEA were predictive for PFS or OS outcome to cediranib treatment compared with placebo in HORIZON II (Figure 3). Similarly, baseline VEGF and CEA levels were not predictive for PFS or OS outcome in cediranibtreated patients $v s$ bevacizumab-treated patients in HORIZON III (Figure 3).

Although there was no strong evidence to suggest that baseline sVEGFR-2 levels predicted for PFS or OS outcome to cediranib treatment, the subgroup of patients with low baseline sVEGFR-2 levels was associated with trends to an improved cediranib PFS effect (HR 0.81 (95\% CI $0.65-1.01$ ); HR $<1$ favours cediranib treatment) and an improved cediranib OS effect (HR 0.90 (95\% CI $0.70-1.15) ; \mathrm{HR}<1$ favours cediranib treatment) in HORIZON II.

\section{DISCUSSION}

A patient selection strategy to effectively identify those patients who are most likely to benefit from treatment with VEGF signalling inhibitors has yet to be characterised. In order to address this unmet need, the prognostic and predictive values of three potential biomarkers for VEGF signalling inhibitors in mCRC, namely VEGF, sVEGFR-2 and CEA, were explored in this study using data and samples from two independent Phase III studies, HORIZON II and HORIZON III (Hoff et al, 2012; Schmoll et al, 2012).

Consistent with previously published studies, most with small patient numbers (Dowlati et al, 2008; Longo and Gasparini, 2008; Jantus-Lewintre et al, 2011; Martins et al, 2011), VEGF levels measured in plasma were strongly prognostic for PFS and OS, with low levels of VEGF resulting in improved patient outcomes compared with high VEGF levels. Although the trial designs of HORIZON II and HORIZON III were different, both studies were 

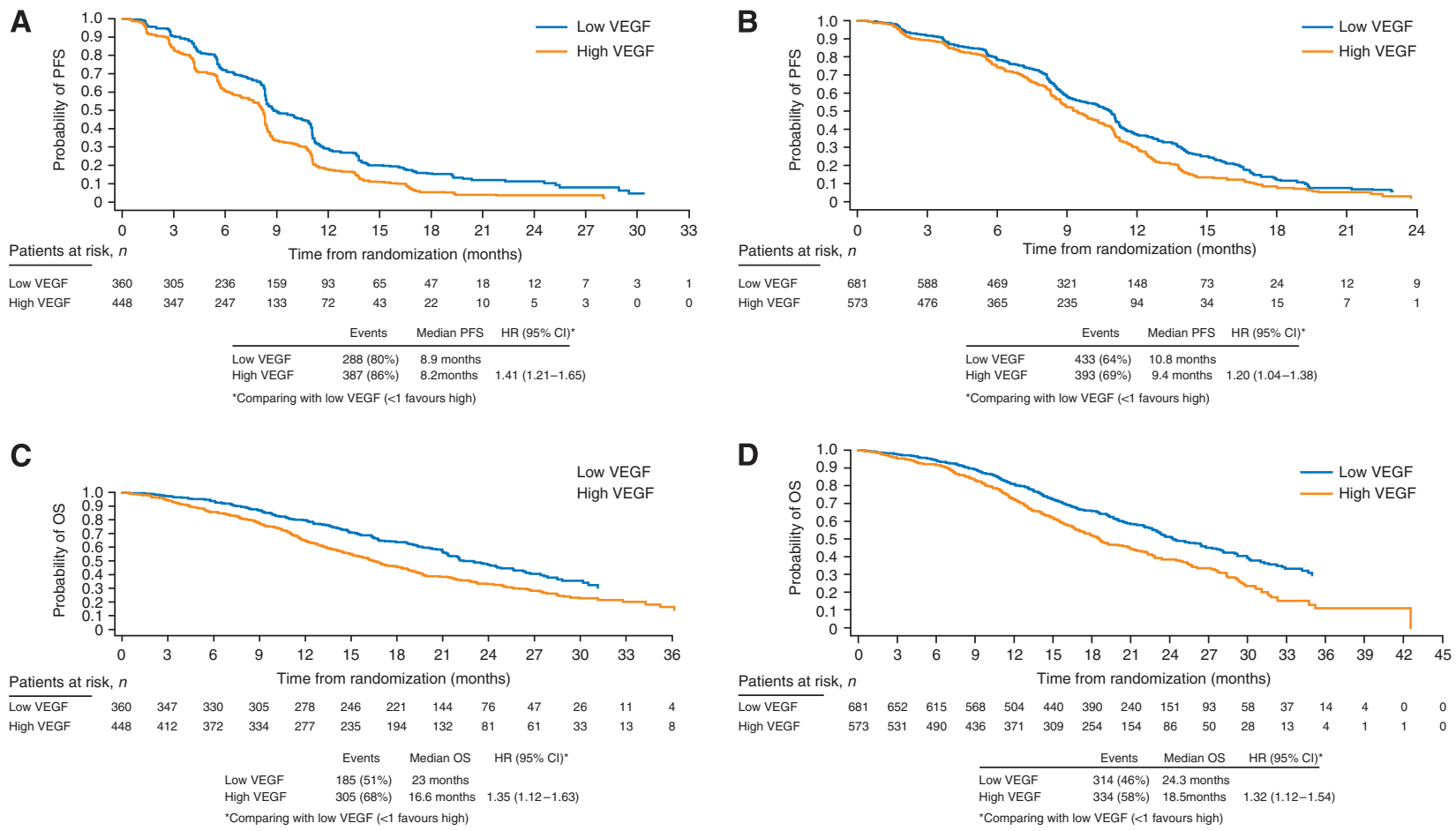

Figure 1. Prognostic effect of VEGF levels on PFS and OS. Effect of baseline VEGF levels on PFS outcome in (A) HORIZON II and (B) HORIZON III and on OS outcome in (C) HORIZON II and (D) HORIZON III.

conducted in patients with previously untreated mCRC and the prognostic value of baseline VEGF was determined across treatment arms allowing data from the trials to be compared. Both studies showed a consistent effect with improved PFS and OS outcomes in patients with low VEGF levels, independent of treatment (FOLFOX/XELOX; FOLFOX/XELOX plus cediranib; mFOLFOX6 plus cediranib; and mFOLFOX6 plus bevacizumab). However, as all patients received background chemotherapy, the possibility cannot be excluded that the observed prognostic effect resulted from the treatment effect of chemotherapy alone. The negative prognostic effect of VEGF on OS was more pronounced in patients with the highest levels of VEGF, as observed when splitting the VEGF patient groups into quartiles; the effect remained consistent between the two independent analyses performed in HORIZON II and HORIZON III. By contrast, and consistent with a previous Phase III trial in a different tumour type (renal cell carcinoma (RCC)) (Escudier et al, 2009; Peña et al, 2010), sVEGFR-2 levels were not prognostic for PFS or OS based on the independent analyses from HORIZON II and HORIZON III.

Previous reports have suggested that pre-operative levels of serum VEGF might be useful for predicting patient outcome after surgery (De Vita et al, 2004); following surgery, VEGF levels tend to decrease compared with pre-operative levels. Evaluation of tumour tissue by immunohistochemistry or reverse transcription PCR, as well as serum/plasma by ELISA methodology, has shown a correlation between high VEGF levels and reduced patient survival in CRC, although a study comparing these methodologies on samples from the same patients has yet to be performed (Longo and Gasparini, 2007). Therefore, although VEGF levels have been measured by multiple methods in tumour tissue and in serum/ plasma, the relationship between tumour tissue and circulating VEGF is still unclear (Martins et al, 2011). However, the increased expression of angiogenic factors has been linked to poor prognosis in patients with cancer; in particular, high levels of circulating VEGF have generally been associated with poor patient outcome (Longo and Gasparini, 2008; Murukesh et al, 2010; Martins et al,
Table 2. Effect of VEGF levels on OS outcome in HORIZON II and HORIZON III: quartile analysis

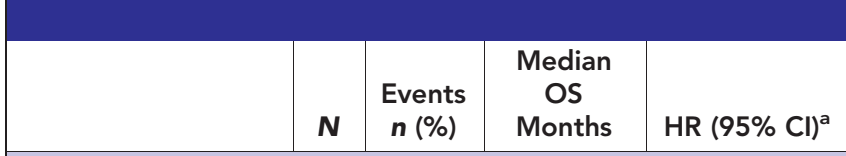

\begin{tabular}{l|l|r|r|c|}
\hline \multicolumn{4}{|l|}{ HORIZON II } & \multicolumn{1}{l|}{} \\
\hline VEGF $\leqslant 49 \mathrm{pg} \mathrm{ml}^{-1}$ & 157 & $75(48)$ & 24.5 & - \\
VEGF $>49-$ & 203 & $110(54)$ & 22.0 & $1.22(0.91-1.64)$ \\
$98 \mathrm{pg} \mathrm{ml}^{-1}$ & & & & \\
VEGF $>98-$ & 231 & $153(66)$ & 18.3 & $1.37(1.03-1.81)$ \\
$209 \mathrm{pg} \mathrm{ml}^{-1}$ & & & & \\
VEGF $>209 \mathrm{pg} \mathrm{ml}^{-1}$ & 217 & $152(70)$ & 14.4 & $1.73(1.29-2.30)$ \\
\hline
\end{tabular}

\begin{tabular}{|c|c|c|c|c|}
\hline \multicolumn{5}{|l|}{ HORIZON III } \\
\hline VEGF $\leqslant 49 \mathrm{pg} \mathrm{ml}^{-1}$ & 373 & $154(41)$ & 26.8 & - \\
\hline $\begin{array}{l}\text { VEGF }>49- \\
98 \mathrm{pg} \mathrm{ml}^{-1}\end{array}$ & 308 & $160(52)$ & 22.7 & $1.26(1.01-1.58)$ \\
\hline $\begin{array}{l}\text { VEGF }>98- \\
209 \mathrm{pg} \mathrm{ml}^{-1}\end{array}$ & 276 & $161(58)$ & 18.8 & $1.41(1.12-1.76)$ \\
\hline VEGF $>209 \mathrm{pg} \mathrm{ml}^{-1}$ & 297 & $173(58)$ & 18.0 & $1.55(1.24-1.94)$ \\
\hline
\end{tabular}

Abbreviations: $\mathrm{Cl}=$ confidence interval; $\mathrm{HR}=$ hazard ratio; $\mathrm{OS}=$ overall survival; sVEGFR-2 = soluble vascular endothelial growth factor (VEGF) receptor- 2 .

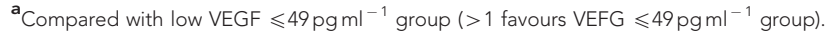

2011). Using protein extracts from surgically resected CRC tumours and normal tissue, Ferroni et al (2005)showed that VEGF levels are higher in tumour tissue than the surrounding normal tissue. In this study, high VEGF levels (cutoff by median) were associated with a worse PFS and OS outcome, independent of treatment. In a meta-analysis of 27 published studies, des Guetz et al (2006) found that VEGF expression, mostly measured by immunohistochemistry in tumours, significantly predicted poor 

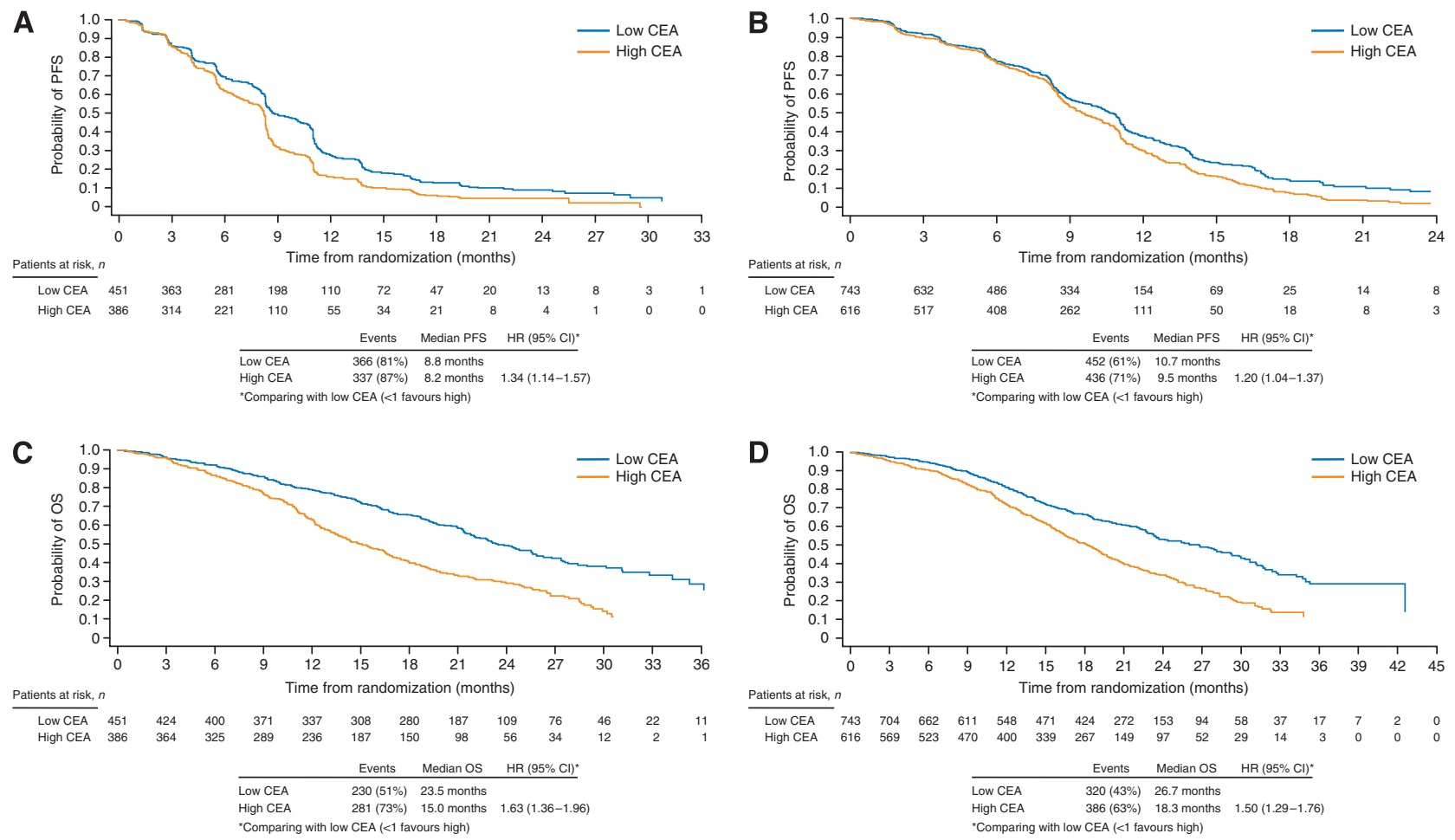

Figure 2. Prognostic effect of CEA levels on PFS and OS. Effect of baseline CEA levels on PFS outcome in (A) HORIZON II and (B) HORIZON III and on OS outcome in (C) HORIZON II and (D) HORIZON III.

\begin{tabular}{|c|c|c|c|c|}
\hline & $\mathbf{N}$ & $\begin{array}{c}\text { Events } \\
n(\%)\end{array}$ & $\begin{array}{l}\text { Median } \\
\text { OS } \\
\text { Months }\end{array}$ & $\operatorname{HR}(95 \% \mathrm{Cl})^{\mathrm{a}}$ \\
\hline \multicolumn{5}{|l|}{ HORIZON II } \\
\hline $\begin{array}{l}\text { CEA } \leqslant 10 \mathrm{pg} \mathrm{ml}^{-1} \\
\text { CEA }>10- \\
50 \mathrm{pg} \mathrm{ml}^{-1} \\
\text { CEA }>50- \\
225 \mathrm{pg} \mathrm{ml}^{-1} \\
\text { CEA }>225 \mathrm{pg} \mathrm{ml}^{-1}\end{array}$ & $\begin{array}{l}249 \\
202 \\
186 \\
200\end{array}$ & $\begin{array}{l}117(47) \\
113(56) \\
132(71) \\
149(75)\end{array}$ & $\begin{array}{l}25.5 \\
21.4 \\
15.4 \\
14.7\end{array}$ & $\begin{array}{c}- \\
1.32(1.02-1.72) \\
1.84(1.43-2.38) \\
1.89(1.46-2.44)\end{array}$ \\
\hline \multicolumn{5}{|l|}{ HORIZON III } \\
\hline $\begin{array}{l}\text { CEA } \leqslant 10 \mathrm{pg} \mathrm{ml}^{-1} \\
\text { CEA }>10- \\
50 \mathrm{pg} \mathrm{ml}^{-1} \\
\text { CEA }>50- \\
225 \mathrm{pg} \mathrm{ml}^{-1} \\
\text { CEA }>225 \mathrm{pg} \mathrm{ml}^{-1}\end{array}$ & $\begin{array}{l}409 \\
334 \\
277 \\
339\end{array}$ & $\begin{array}{l}158(39) \\
162(49) \\
167(60) \\
219(65)\end{array}$ & $\begin{array}{l}28.1 \\
23.6 \\
19.6\end{array}$ & $\begin{array}{c}- \\
1.17(0.94-1.46) \\
1.62(1.30-2.02) \\
1.63(1.31-2.03)\end{array}$ \\
\hline $\begin{array}{l}\text { Abbreviations: } \mathrm{CEA}=\mathrm{ca} \\
\mathrm{HR}=\text { hazard ratio; } \mathrm{OS}= \\
{ }^{\mathrm{a}} \text { Compared with low } \mathrm{CE}\end{array}$ & $\begin{array}{l}\text { II survi } \\
10 \mathrm{pg} \mathrm{m}\end{array}$ & $\begin{array}{l}\text { hic antigen } \\
\text { al. } \\
-1 \text { group }\end{array}$ & unfidenc & Dpg ml-1 \\
\hline
\end{tabular}

relapse-free survival and OS. However, in a different exploratory analysis in patients with $\mathrm{mCRC}$, baseline VEGF expression assessed by in situ hybridisation and immunohistochemistry was not a significant prognostic factor (Jubb et al, 2006).

In a Phase II/III study of carboplatin, docetaxel and bevacizumab for the treatment of non-small-cell lung cancer (NSCLC), patients with low VEGF levels showed a better prognosis than those with high VEGF levels (Dowlati et al, 2008). Furthermore, in a study of 432 patients with advanced NSCLC who were treated

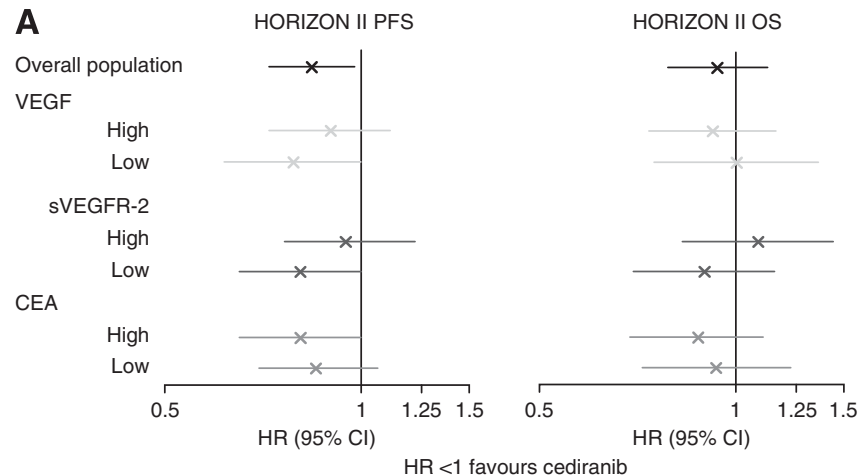

B

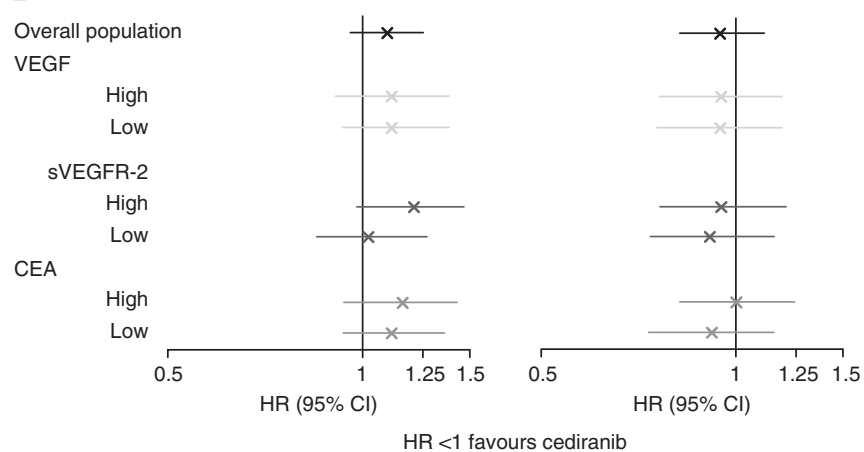

Figure 3. Predictive effects of baseline VEGF, sVEGFR-2 and CEA. Predictive effect of baseline VEGF, sVEGFR-2 and CEA levels on PFS and OS outcome in (A) HORIZON II and (B) HORIZON III.

with cisplatin and docetaxel, those patients with a combination of high VEGF-A and low sVEGFR-2 plasma levels were associated with the worst prognosis (Jantus-Lewintre et al, 2011). In a recent 
study (Hegde et al, 2013), evaluating VEGF levels across multiple clinical studies with bevacizumab either alone or in combination with other agents, 1816 samples from patients with multiple tumour types (mCRC, NSCLC, mRCC) showed that patients with high VEGF levels in plasma had an adverse prognostic effect on OS, independent of treatment. These data, although obtained across multiple studies using a different VEGF signalling inhibitor and an assay that was specifically established to evaluate these samples, are in line with our findings. In a Phase III study testing sorafenib vs placebo (with a crossover option to sorafenib) in patients with RCC, high baseline plasma levels of VEGF were associated with inferior PFS and OS outcomes in the placebo control arm, although baseline sVEGFR-2 levels were not prognostic (Escudier et al, 2009; Peña et al, 2010).

In this analysis, high baseline levels of CEA were associated with a poor prognosis (PFS and OS) that was consistent across HORIZON II and HORIZON III. When patients were split into quartiles by baseline CEA levels, patients with the highest CEA levels in both the studies had the worst median OS, independent of treatment. In contrast to the VEGF and sVEGFR-2 data, which were measured centrally by standard methodology, the CEA data were not generated centrally but instead obtained as part of the data collection process from the individual sites in the two studies. Consequently, the methodology used for the determination of CEA levels was at the discretion of each site. The data, showing a clear negative prognostic effect of CEA on PFS and OS in two independent studies, suggest that the methodology used for the determination of CEA does not significantly influence the results and, therefore, that investigator assessment of CEA could be used in future studies.

CEA levels have previously been shown to be both a prognostic and predictive factor in multiple cancer types (Harrison et al, 1997; Andicoechea et al, 1998; Ebeling et al, 2002; Okamoto et al, 2005). In an evaluation of 214 patients with CRC, high pre-operative serum levels of CEA were associated with significantly reduced OS vs low serum CEA levels (Andicoechea et al, 1998). A retrospective analysis of 105 patients with NSCLC revealed that elevated baseline CEA levels significantly increased sensitivity to gefitinib treatment (Okamoto et al, 2005). VEGF levels have been shown to correlate with CEA levels in tumour tissue and the surrounding mucosa. However, in a small study (69 patients) of treatment-naive CRC patients, Ferroni et al (2006) measured CEA in protein extracts from tumours obtained during surgery and found that CEA and VEGF levels had an independent prognostic value in predicting relapse-free survival and OS, independent of Duke's stage.

To evaluate the predictive value of VEGF, sVEGFR-2 and CEA for the treatment outcome with cediranib compared with the control arm, data from HORIZON II and HORIZON III were interpreted independently because the control arms were different (chemotherapy alone in HORIZON II and bevacizumab plus chemotherapy in HORIZON III). Overall, in both the trials, baseline levels of VEGF, sVEGFR-2 and CEA were not predictive for treatment outcome, although the subgroups with low baseline sVEGFR-2 levels were associated with a trend towards an improved cediranib PFS effect in both the studies and an improved OS effect in HORIZON II. However, it should be noted that in each case the difference in treatment effect between the subgroups was not large and the confidence intervals overlapped widely.

Although there are a large number of publications studying the prognostic value of VEGF in different tumour types, there are fewer reports on the potential predictive value of VEGF and sVEGFR-2 from studies with VEGF signalling inhibitors. Of the studies performed with VEGF signalling inhibitors and, in particular, bevacizumab, many did not evaluate biomarkers and those that did are generally single-arm studies. Most randomized studies with bevacizumab that have studied VEGF in serum or tumour tissue have not found a correlation between VEGF expression or plasma levels and treatment; these included one study each in RCC, metastatic breast cancer, pancreatic cancer and mCRC (Jubb et al, 2006; Longo and Gasparini, 2007; Longo and Gasparini, 2008). In a Phase II/III study in NSCLC, patients with high VEGF levels were more likely to respond to treatment with bevacizumab plus chemotherapy $v s$ chemotherapy alone, but this was not predictive of PFS and OS (Dowlati et al, 2008). Our data are confirmed by a newly published investigation of multiple bevacizumab studies in patients with mCRC, NCSLC and mRCC, which also showed that baseline levels of VEGF cannot be used as a predictive marker for bevacizumab response (Hegde et al, 2013). In a Phase III trial in RCC, the VEGFR TKI sorafenib showed benefit in both the high and low plasma VEGF groups, although there was a trend towards increased benefit from sorafenib treatment in patients with high VEGF levels compared with patients with low VEGF levels (Escudier et al, 2009). Finally, in a single-arm study of FOLFIRI plus bevacizumab in patients with first-line mCRC, Kopetz et al (2010) found that baseline levels of neither VEGF nor sVEGFR-2 predicted for treatment outcome.

There are, however, some studies where VEGF and sVEGFR-2 levels have been shown to be predictive for treatment outcome in patients receiving VEGF signalling inhibitors. An exploratory study with the VEGFR TKI vandetanib revealed that low levels of circulating VEGF may be predictive of improved PFS in patients with advanced NSCLC receiving vandetanib $v s$ gefitinib or vandetanib plus docetaxel $v s$ docetaxel alone (Hanrahan et al, 2009); however, this finding was not confirmed in Phase III trials (Herbst et al, 2010; de Boer et al, 2011; Lee et al, 2012). Recently, the debate on VEGF and sVEGFR-2 as potential predictive biomarkers for VEGF signalling inhibitors was reopened following retrospective subset analyses of the AVADO study. This study used a novel ELISA-based multiplex analysis and showed that high baseline VEGF and sVEGFR-2 were predictive for a better PFS outcome in metastatic breast cancer patients treated with bevacizumab plus docetaxel vs docetaxel alone (Miles et al, 2010).

The data from HORIZON II, comparing the VEGF signalling inhibitor cediranib with placebo on the background of chemotherapy, although concurrent with the recently published evaluation of multiple studies by Hegde et al (2013), are not consistent with data from the AVADO study (Miles et al, 2010). However, several differences between these studies could potentially account for the observed discrepancy, including differences in tumour type, VEGF signalling inhibitor, backbone chemotherapy and the assays used for analysis. Therefore, although high VEGF and sVEGFR-2 levels might potentially be predictive for benefit from bevacizumab treatment in combination with docetaxel in metastatic breast cancer, this effect does not appear to translate across tumours, agents and studies. For cediranib, the data presented here suggest that baseline levels of neither VEGF nor sVEGFR-2 are predictive for outcome on cediranib treatment.

In summary, in this retrospective subset analysis of over 2000 patients, baseline levels of VEGF and CEA were confirmed as prognostic biomarkers for both PFS and OS in patients with mCRC, independent of treatment. High baseline values of these two biomarkers were associated with a worse PFS and OS outcome. Thus, the prognostic value of CEA and VEGF that has been reported previously in several tumour types, mostly in small cohorts of patients, was confirmed by this analysis of two large independent studies, and these biomarkers should be considered when designing studies in mCRC. These data also showed that treatment outcome with cediranib, independent of the prognostic relevance, cannot be predicted by baseline levels of VEGF, sVEGFR-2 or CEA. Patients with lower sVEGFR-2 levels may derive greater benefit from treatment with cediranib; however, the effect in this study was small and would need to be confirmed in a prospective trial. 


\section{ACKNOWLEDGEMENTS}

Funding for this study was provided by AstraZeneca. Writing support was provided by Ben Clarke of Mudskipper Bioscience and funded by AstraZeneca.

\section{CONFLICT OF INTEREST}

JMJ, JDR, LB, MT, SRM, DW are AstraZeneca employees and own stock. H-JS has received payment for consultancy and honorarium from Roche, Merck, Sanofi and AstraZeneca. PMH has received payment for consultancy and participation in AstraZeneca advisory board.

\section{AUTHOR CONTRIBUTIONS}

Conception and design: JDR, JMJ, H-JS, PMH. Acquisition of data: SRM. Analysis and interpretation of data: MT, SM, LB, JDR, JMJ, HJS, DW, PMH. Writing, review and/or revision of the manuscript: MT, SRM, LB, JDR, JMJ, PMH, H-JS, DW. Study supervision: JDR.

\section{REFERENCES}

Amaya H, Tanigawa N, Lu C, Matsumura M, Shimomatsuya T, Horiuchi T, Muraoka R (1997) Association of vascular endothelial growth factor expression with tumor angiogenesis, survival and thymidine phosphorylase/platelet-derived endothelial cell growth factor expression in human colorectal cancer. Cancer Lett 119: 227-235.

Andicoechea A, Vizoso F, Alexandre E, Cuesta E, Cruz DM, Miera L, GarciaMuniz JL, Martinez E, Ruibal A (1998) Preoperative carbohydrate antigen 195 (CA195) and CEA serum levels as prognostic factors in patients with colorectal cancer. Int J Biol Markers 13: 158-164.

de Boer RH, Arrieta Ó, Yang C-H, Gottfried M, Chan V, Raats J, De Marinis F, Abratt RP, Wolf J, Blackhall FH, Langmuir P, Milenkova T, Read J, Vansteenkiste JF (2011) Vandetanib plus pemetrexed for the second-line treatment of advanced non-small-cell lung cancer: A randomized, doubleblind Phase III trial. J Clin Oncol 29: 1067-1074.

De Vita F, Orditura M, Lieto E, Infusino S, Morgillo F, Martinelli E, Castellano P, Romano C, Ciardiello F, Catalano G, Pignatelli C, Galizia G (2004) Elevated perioperative serum vascular endothelial growth factor levels in patients with colon carcinoma. Cancer 100: 270-278.

des Guetz G, Uzzan B, Nicolas P, Cucherat M, Morere J-F, Benamouzig R, Breau J-L, Perret G-Y (2006) Microvessel density and VEGF expression are prognostic factors in colorectal cancer. Meta-analysis of the literature. Br J Cancer 94: 1823-1832.

Dowlati A, Gray R, Sandler AB, Schiller JH, Johnson DH (2008) Cell adhesion molecules, vascular endothelial growth factor, and basic fibroblast growth factor in patients with non-small cell lung cancer treated with chemotherapy with or without bevacizumab-an Eastern Cooperative Oncology Group Study. Clin Cancer Res 14: 1407-1412.

Drevs J, Siegert P, Medinger M, Mross K, Strecker R, Zirrgiebel U, Harder J, Blum H, Robertson J, Jürgensmeier JM, Puchalski TA, Young H, Saunders O, Unger C (2007) Phase I clinical study of AZD2171, an oral vascular endothelial growth factor signaling inhibitor, in patients with advanced solid tumors. J Clin Oncol 25: 3045-3054.

Ebeling FG, Stieber P, Untch M, Nagel D, Konecny GE, Schmitt UM, FatehMoghadam A, Seidel D (2002) Serum CEA and CA 15-3 as prognostic factors in primary breast cancer. Br J Cancer 86: 1217-1222.

Escudier B, Eisen T, Stadler WM, Szczylik C, Oudard S, Staehler M, Negrier S, Chevreau C, Desai AA, Rolland F, Demkow T, Hutson TE, Gore M, Anderson S, Hofilena G, Shan M, Pena C, Lathia C, Bukowski RM (2009) Sorafenib for treatment of renal cell carcinoma: Final efficacy and safety results of the phase III treatment approaches in renal cancer global evaluation trial. J Clin Oncol 27: 3312-3318.

Ferroni P, Palmirotta R, Spila A, Martini F, Formica V, Portarena I, Del Monte G, Buonomo O, Roselli M, Guadagni F (2006) Prognostic value of carcinoembryonic antigen and vascular endothelial growth factor tumor tissue content in colorectal cancer. Oncology 71: 176-184.

Ferroni P, Spila A, Martini F, D’Alessandro R, Mariotti S, Del Monte G, Graziano P, Buonomo O, Guadagni F, Roselli M (2005) Prognostic value of vascular endothelial growth factor tumor tissue content of colorectal cancer. Oncology 69: 145-153.

Hanrahan EO, Ryan AJ, Mann H, Kennedy SJ, Langmuir P, Natale RB, Herbst RS, Johnson BE, Heymach JV (2009) Baseline vascular endothelial growth factor concentration as a potential predictive marker of benefit from vandetanib in non-small cell lung cancer. Clin Cancer Res 15: 3600-3609.

Harrison LE, Guillem JG, Paty P, Cohen AM (1997) Preoperative carcinoembryonic antigen predicts outcomes in node-negative colon cancer patients: a multivariate analysis of 572 patients. J Am Coll Surg 185: 55-59.

Heckman CA, Holopainen T, Wirzenius M, Keskitalo S, Jeltsch M, Yla-Herttuala S, Wedge SR, Jürgensmeier JM, Alitalo K (2008) The tyrosine kinase inhibitor cediranib blocks ligand-induced vascular endothelial growth factor receptor-3 activity and lymphangiogenesis. Cancer Res 68: 4754-4762.

Hegde PS, Jubb AM, Chen D, Li NF, Meng G, Bernaards C, Elliott R, Scherer S, Chen DS (2013) Predictive impact of circulating vascular endothelial growth factor in 4 Phase III trials evaluating bevacizumab. Clin Cancer Res 19: 929-937.

Herbst RS, Sun Y, Eberhardt WE, Germonpre P, Saijo N, Zhou C, Wang J, Li L, Kabbinavar F, Ichinose Y, Qin S, Zhang L, Biesma B, Heymach JV, Langmuir P, Kennedy SJ, Tada H, Johnson BE (2010) Vandetanib plus docetaxel versus docetaxel as second-line treatment for patients with advanced non-small-cell lung cancer (ZODIAC): a double-blind, randomised, phase 3 trial. Lancet Oncol 11: 619-626.

Hoff PM, Hochhaus A, Pestalozzi BC, Tebbutt NC, Li J, Kim TW, Koynov KD, Kurteva G, Pintér T, Cheng Y, van Eyll B, Pike L, Fielding A, Robertson JD, Saunders MP. on behalf of the HORIZON II study group (2012) Cediranib plus FOLFOX/CAPOX versus placebo plus FOLFOX/ CAPOX in patients with previously untreated metastatic colorectal cancer: A randomized, double-blind, Phase III study (HORIZON II). J Clin Oncol 30: 3596-3603.

Jacobsen J, Rasmuson T, Grankvist K, Ljungberg B (2000) Vascular endothelial growth factor as prognostic factor in renal cell carcinoma. J Urol 163: 343-347.

Jantus-Lewintre E, Sanmartín E, Sirera R, Blasco A, Sanchez JJ, Tarón M, Rosell R, Camps C (2011) Combined VEGF-A and VEGFR-2 concentrations in plasma: diagnostic and prognostic implications in patients with advanced NSCLC. Lung Cancer 74: 326-331.

Jubb AM, Hurwitz HI, Bai W, Holmgren EB, Tobin P, Guerrero AS, Kabbinavar F, Holden SN, Novotny WF, Frantz GD, Hillan KJ, Koeppen $\mathrm{H}$ (2006) Impact of vascular endothelial growth factor-A expression, thrombospondin-2 expression, and microvessel density on the treatment effect of bevacizumab in metastatic colorectal cancer. J Clin Oncol 24: 217-227.

Kopetz S, Hoff PM, Morris JS, Wolff RA, Eng C, Glover KY, Adinin R, Overman MJ, Valero V, Wen S, Lieu C, Yan S, Tran HT, Ellis LM, Abbruzzese JL, Heymach JV (2010) Phase II trial of infusional fluorouracil, irinotecan, and bevacizumab for metastatic colorectal cancer: efficacy and circulating angiogenic biomarkers associated with therapeutic resistance. J Clin Oncol 28: 453-459.

Lee JS, Hirsh V, Park K, Qin S, Blajman CR, Perng R-P, Chen Y-M, Emerson L, Langmuir P, Manegold C (2012) Vandetanib versus placebo in patients with advanced non-small-cell lung cancer after prior therapy with an epidermal growth factor receptor tyrosine kinase inhibitor: a randomized, double-blind Phase III trial (ZEPHYR). J Clin Oncol 30: 1114-1121.

Locker GY, Hamilton S, Harris J, Jessup JM, Kemeny N, Macdonald JS, Somerfield MR, Hayes DF, Bast Jr RC (2006) ASCO 2006 update of recommendations for the use of tumor markers in gastrointestinal cancer. J Clin Oncol 24: 5313-5327.

Longo R, Gasparini G (2007) Challenges for patient selection with VEGF inhibitors. Cancer Chemother Pharmacol 60: 151-170.

Longo R, Gasparini G (2008) Anti-VEGF therapy: the search for clinical biomarkers. Expert Rev Mol Diagn 8: 301-314.

Martins SF, Reis RM, Rodrigues AM, Baltazar F, Filho AL (2011) Role of endoglin and VEGF family expression in colorectal cancer prognosis and anti-angiogenic therapies. World J Clin Oncol 2: 272-280.

Miles DW, de Haas SL, Dirix L, Chan A, Pivot X, Tomczak P, Provencher L, Delmar P, Scherer S (2010) Plasma biomarker analyses in the AVADO 
Phase III randomized study of first-line bevacizumab + docetaxel in patients with human epidermal growth factor receptor (HER) 2-negative metastatic breast cancer. Cancer Res 70(24 Suppl 2): Abstract nr P2-16-04.

Murukesh N, Dive C, Jayson GC (2010) Biomarkers of angiogenesis and their role in the development of VEGF inhibitors. Br J Cancer 102: $8-18$.

Okamoto T, Nakamura T, Ikeda J, Maruyama R, Shoji F, Miyake T, Wataya H, Ichinose Y (2005) Serum carcinoembryonic antigen as a predictive marker for sensitivity to gefitinib in advanced non-small cell lung cancer. Eur $J$ Cancer 41: 1286-1290.

Peña C, Lathia C, Shan M, Escudier B, Bukowski RM (2010) Biomarkers predicting outcome in patients with advanced renal cell carcinoma: results from sorafenib phase III treatment approaches in Renal Cancer Global Evaluation Trial. Clin Cancer Res 16: 4853-4863.

Rydén L, Jirstrom K, Haglund M, Stål O, Fernö M (2010) Epidermal growth factor receptor and vascular endothelial growth factor receptor 2 are specific biomarkers in triple-negative breast cancer. Results from a controlled randomized trial with long-term follow-up. Breast Cancer Res Treat 120: 491-498.

Schmoll H-J, Cunningham D, Sobrero A, Karapetis CS, Rougier P, Koski SL, Kocakova I, Bondarenko I, Bodoky G, Mainwaring P, Salazar R, Barker P, Mookerjee B, Robertson J, Van Cutsem E. on behalf of the HORIZON III study group (2012) Cediranib with mFOLFOX6 versus bevacizumab with mFOLFOX6 as first-line treatment for patients with advanced colorectal cancer: a double-blind, randomized Phase III study (HORIZON III). J Clin Oncol 30: 3588-3595.

Seto T, Higashiyama M, Funai H, Imamura F, Uematsu K, Seki N, Eguchi K, Yamanaka T, Ichinose Y (2006) Prognostic value of expression of vascular endothelial growth factor and its flt-1 and KDR receptors in stage I nonsmall-cell lung cancer. Lung Cancer 53: 91-96.

Wedge SR, Kendrew J, Hennequin LF, Valentine PJ, Barry ST, Brave SR, Smith NR, James NH, Dukes M, Curwen JO, Chester R, Jackson JA, Boffey SJ, Kilburn LL, Barnett S, Richmond GH, Wadsworth PF, Walker M, Bigley AL, Taylor ST, Cooper L, Beck S, Jürgensmeier JM, Ogilvie DJ (2005) AZD2171: a highly potent, orally bioavailable, vascular endothelial growth factor receptor-2 tyrosine kinase inhibitor for the treatment of cancer. Cancer Res 65: 4389-4400.

Xia G, Kumar SR, Hawes D, Cai J, Hassanieh L, Groshen S, Zhu S, Masood R, Quinn DI, Broek D, Stein JP, Gill PS (2006) Expression and significance of vascular endothelial growth factor receptor 2 in bladder cancer. J Urol 175: $1245-1252$.

This work is published under the standard license to publish agreement. After 12 months the work will become freely available and the license terms will switch to a Creative Commons AttributionNonCommercial-Share Alike 3.0 Unported License. 